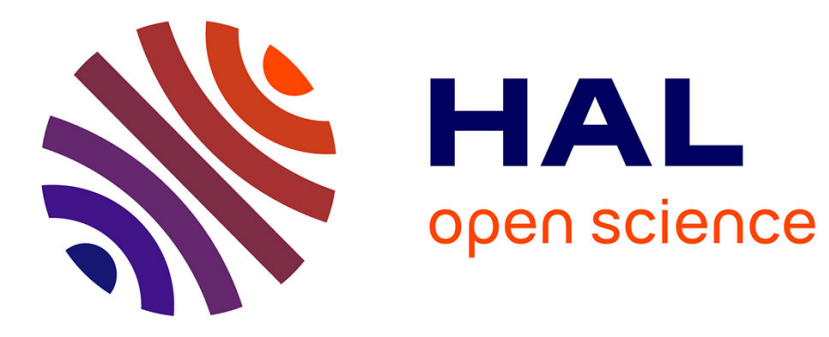

\title{
Odor discrimination assessment with an automated olfactometric method in a prosimian primate, Microcebus murinus.
}

\author{
Marine Joly, Bernard Michel, Bertrand Deputte, Jean-Michel Verdier
}

\section{To cite this version:}

Marine Joly, Bernard Michel, Bertrand Deputte, Jean-Michel Verdier. Odor discrimination assessment with an automated olfactometric method in a prosimian primate, Microcebus murinus.. Physiology \& behavior, 2004, 82 (2-3), pp.325-9. 10.1016/j.physbeh.2004.03.019 . inserm-00143511

HAL Id: inserm-00143511 https://www.hal.inserm.fr/inserm-00143511

Submitted on 25 Apr 2007

HAL is a multi-disciplinary open access archive for the deposit and dissemination of scientific research documents, whether they are published or not. The documents may come from teaching and research institutions in France or abroad, or from public or private research centers.
L'archive ouverte pluridisciplinaire HAL, est destinée au dépôt et à la diffusion de documents scientifiques de niveau recherche, publiés ou non, émanant des établissements d'enseignement et de recherche français ou étrangers, des laboratoires publics ou privés. 


\section{Odor discrimination assessment with an automated olfactometric}

\section{method in a prosimian primate, Microcebus murinus}

Marine Joly $^{\mathrm{a}}$, Bernard Michel ${ }^{\mathrm{b}}$, Bertrand Deputte ${ }^{\mathrm{c}}$ and Jean-Michel Verdier ${ }^{\mathrm{a}^{*}}$

a Laboratoire "Vieillissement Cérébral et Pathogenèse des Maladies Neurodégénératives",

EPHE, Université Montpellier II, Place E. Bataillon, CC94, 34095 Montpellier Cedex 05,

France

${ }^{\mathrm{b}}$ Unité de Neurogériatrie, Hôpital Sainte-Marguerite, Marseille, France

${ }^{\mathrm{c}}$ Ecole Nationale Vétérinaire d'Alfort, Maisons-Alfort, France

*Corresponding author. Tel./fax: +33-4-67-14-32-91. E-mail: verdier@univ-montp2.fr

Running head: Odor discrimination in M. murinus 


\begin{abstract}
The present study was aimed at adapting an automated olfactometer designed for use with rodents to a nocturnal lemur Microcebus murinus. This apparatus allows rigorous control of odor stimuli. We show that Microcebus murinus could remain quiet and attentive for about 20 minutes in the test chamber, allowing daily sessions of 40 consecutive trials. This allowed us to train Microcebus murinus subjects to learn a go/no-go discrimination procedure using fruity odor cues. Each of 7 subjects reached or exceeded a criterion of 33 correct responses in a block of 40 trials in a range of 4 to 14 training sessions. When trained on an odor reversal task, performance initially dropped sharply, followed by rapid acquisition of the new task. These outcomes demonstrate that, like rodents, Microcebus murinus can be trained using operant conditioning in an automated olfactometer. This species should prove useful for investigating cognitive capacities and neurodegenerative disease in a primitive primate model.
\end{abstract}

Keywords: Microcebus murinus; Cognitive capacities; Odor discrimination; Olfactometry; Go/no-go task 


\section{Introduction}

Prosimians are considered as primitive primates because they have anatomical and biological features not found in anthropoid primates. Most are nocturnal and have layer in the retina (tapetum) that reflects light, thus enhancing night vision [1]. Behavioral observations suggest that olfaction could play an important role in communication. For instance, the gray mouse lemur, Microcebus murinus, a small (60-100 g) nocturnal Malagasy prosimian uses "urine washing" to mark its territory [2;3]. Information present in urine has been shown to be essential for sexual regulation [4;5;6], and can modify sex ratio at birth [7]. Despite the potential use of prosimians for studies on the evolution of cognitive function and the neurobiology of degenerative diseases [8], to our knowledge, no empirical studies have been examined odor detection or discrimination in this species. In addition, there is no evidence that captive individuals can be trained using traditional conditioning methods. The aim of this study was to determine if the gray mouse lemur could be trained for olfactory discriminative tasks using an olfactometer and standard operant conditioning methods that have proven useful in examining olfactory-based cognitive function in rodents [9].

\section{Materials and Methods}

\section{Animal subjects}

Seven young adult females $(3.5 \pm 0.5$ years old $)$ were subjects of this experiment. They were all born in captivity in our laboratory breeding colony. They had no previous experience with cognitive testing and were naive to the procedures described below. Subjects were maintained under a 14h:10h light:dark cycle and housed individually during the experiment. 
They were fed daily with one piece of fruit (apple or banana) after testing and could drink $a d$ libitum during the test. Weight was monitored weekly, and maintained between 60 and $70 \mathrm{~g}$. Because these animals are nocturnal, testing was performed during the dark phase of their cycle under a red light. The experiments were approved by the local ethic committee (Comité d'Ethique Régional en Expérimentation Animale, Languedoc-Roussillon, CE-LR-0303).

\section{Capture and transport}

All tests were performed in an isolated experimental room. To avoid stressful conditions due to capture and transport, animals were previously trained to enter a wooden box in which they were carried to the olfactometer chamber and back to their home cage. Entering the transport box was rewarded with a small piece of sweetened cereal.

\section{Apparatus and odors}

We used an eight channel liquid dilution olfactometer (Knosys Olfactometers; http://www.chemsenses.com) identical to that described in detail by Schellinck et al. [10]. Briefly, the unit consists of an operant chamber equipped with a glass odor sampling tube and an eight-channel odor generator (Fig. 1). Odorants were nature-like aromas from Givaudan (Dubendorf, Suisse). Odor concentrations used were those indicated by the manufacturer to elaborate fruity drinks.

\section{Conditioning procedures}

The go-no go procedures described in detail by Schellinck et al. [10] were used for initial training and discrimination training. The software programs, provided by Knosys Olfactometers, for training rodents were used. Initial training required that the lemur inserted its snout in the odor delivery port and responded by licking on a reinforcement tube when an 
odor was detected [11]. Ethyl acetate diluted to $2 \%$ in water was used as the training stimulus. Once the animal responded reliably, it was trained on a second odor detection task in which strawberry $(0.015 \%)$ served as the $\mathrm{S}+$ stimulus and odorless solvent (water) served as the Sstimulus. S+ and S- stimuli were presented in a modified random order in each session. Responding (licking at the reinforcement tube) in the presence of the $\mathrm{S}+$ odor was rewarded with a drop of about $0.05 \mathrm{~mL}$ of apple juice and scored as a correct trial (hit). Responding in the presence of S- stimulus was not rewarded and was scored as an error (false alarm). Not responding in the presence of the $\mathrm{S}+$ stimulus was scored as an error (miss) while not responding in the presence of the S- stimulus was scored as a correct response (correct rejection). Training on this task was carried out for 40 trial sessions until the subject reached the criterion performance of $82.5 \%(\mathrm{p}<0.0001)$, i.e. 33 correct responses. Next, each lemur was tested on two others tasks. Then, training was continued in which the $\mathrm{S}+$ stimulus was strawberry $(0.015 \%)$ and the S- stimulus was pear $(0.05 \%)$. When animals achieved criterion on this task, the S+ and S- assignments of the stimuli were reversed (the pear odor served as $\mathrm{S}+$ and the strawberry odor served as S-).

\section{Control parameters}

The computer program recorded each trial response and licks that also occurred when the final valve was closed (i.e. when no odor was present in the sampling tube). This licking parameter was used to determine whether animals used other cues just before odors sampling. If animals only used odor cues, licks during this period should not be different between S+ and S- trials.

\section{Data analysis}


The criterion was set at $81 \%$ correct responses (binomial test, $\mathrm{p}=0.0001$ ). Discrimination was then achieved when a minimum of 33 correct responses out of $40(82.5 \%)$ was given by subject. The task was considered acquired when mouse lemur reached this criterion in two consecutive sessions. The percentage of correct responses was calculated for each individual. Results were expressed as mean number of sessions \pm SD. Comparison between two tasks were performed using the Wilcoxon Signed-rank Test [12].

\section{Results}

\section{Initial Training}

Slotnick and colleagues $[10 ; 13]$ reported that initial training requiring rodents to sample an odor stimulus and respond for a water reward, can be accomplished in one to three 45 to 50 min sessions. With our procedures, the gray mouse lemurs appeared to be motivated only for the first $20 \mathrm{~min}$ of the session and, hence, around 5-8 sessions were required for initial training ( $\mathrm{S}+$ only trials). Initially, subjects were maintained on a water deprivation schedule and correct responses were reinforced with water. However, subjects showed little interest in water reward. Among different liquids tested in these exploratory sessions, apple juice proved to be the most rewarding liquid and was adopted as the reinforcer for all subsequent sessions. At the end of the training period, all animals licked the reward tube after an odor sample of, on average, $1.2 \mathrm{~s}$.

\section{Fruity odor vs pure air discrimination}

After initial training, subjects immediately inserted their snouts into the sampling tube after entering the test chamber. No aversion was observed when a new odor was tested. In the first strawberry detection session, all animals licked the tube when strawberry odor was 
presented and withdrew when pure air (S-) was the stimulus. Lemurs achieved criterion, on average, in 9.4 sessions but there was considerable variability in performance among subjects: the fastest learner needed only 4 sessions to reach criterion while the slowest learner needed 14 sessions (Fig. 2). In sessions with scores over the criterion, all the animals made an equal number of misses and false alarms $(\mathrm{W}=14, \mathrm{p}=0.14)$.

\section{Transfer task: two fruity odors discrimination}

In the discrimination task, S- was changed from water to pear odor. Mean accuracy in first session was $69 \%$ and most errors were false alarms. In subsequent sessions, performance accuracy steadily increased and, on average, subjects required $3.6 \pm 0.8$ sessions to discriminate between the two fruity odors (Fig. 2). Individual differences were again observed: the two best performers had scores of $77.5 \%$ correct during the first session while the worse performer score was $52.5 \%$. In sessions with scores over the criterion, false alarms were more frequent than misses $(\mathrm{W}=21, \mathrm{p}=0.03)$.

\section{Reversal task}

In the reversal learning task, strawberry odor served as S- and pear odor served as $\mathrm{S}+$. The mean percentage of correct responses in the first session was $24.3 \pm 11.9$. Performance gradually improved and all animals learned to respond to pear and inhibited responding to strawberry. On average, criterion was achieved in $9.6 \pm 3.4$ sessions. Variability in performance was even greater in this task; criterion was achieved in 5 sessions for the fastest learner and 16 sessions for the slowest learner. In sessions with scores over the criterion, false alarms were more frequent than misses $(\mathrm{W}=28, \mathrm{p}=0.02)$. This observation indicated that animals identified more easily the new $\mathrm{S}+$ whereas inhibition of licking behavior in presence of S- (previous $\mathrm{S}+$ ) was more difficult. 


\section{Comparison between tasks performances}

All subjects achieved criterion more quickly on the two odor discrimination task than on the strawberry detection task (3.6 $\pm 0.8 v s 9.4 \pm 3.5$, respectively; $W=21, p=0.03$; Fig. 2$)$ but, as expected, required significantly more sessions to reach the criterion on the reversal learning task (9.6 \pm 3.4 vs $3.6 \pm 0.8$, respectively; $W=28, p=0.02$; Fig. 2). As an example, the performance of one female, over the 3 tasks, is given in Figure 3. As shown in figure 4, acquisition in each task was largely function of inhibiting responses to the S- stimulus. Even the initial increase in misses on the reversal task was transient and after the first session few or no errors were made on the $\mathrm{S}+$ stimulus.

\section{Discussion}

The present study provides the first demonstration of odor detection, discrimination and reversal learning in a small prosimian primate, the gray mouse lemur Microcebus murinus. The olfactometer designed for use with rats was well suited for the lemur and allowed us to investigate olfactory discriminative abilities with rigorous control of odor stimuli and odor sampling behavior. The advantages of olfactometric delivery of odors over methods in which odors are usually diffused from a point source have been described in detail [14]. Of particular importance in using very shy subjects such as lemurs, the automated system minimized handling of subjects and the potential distractions of trial by trial interventions by the experimenter. Moreover, with this method, a single trial lasted only approximately $10 \mathrm{~s}$., allowing us to complete multiple trials within a short time-span. In this

study, we reported the use of a go-no go procedure that is applied to the gray mouse lemur for the first time. Our results provide empirical confirmation of suggestions from field studies 
that lemurs are responsive to odors. The methods used in the present study could easily be adapted to assess the ability of these animals to detect and discriminate among speciesspecific odors thought to be used in social communication [1].

Automated procedures have already been validated to test discriminative abilities in rodents $[11 ; 15]$. Conversely, because the development of adapted devices are limited by primate size, to our knowledge, only one automated olfactometric study has been reported with non-human primates [16]. In this study, Glaser and colleagues built an automated device to assess odor detection threshold in the pygmy marmoset. They showed that the pygmy marmoset was able to discriminate between vanillin odor and clean air in a forced-choice triangle task, and that the vanillin detection threshold of this platyrrhine species is not different than that of humans [16]. That report and our results indicate that automated olfactometers may prove useful for exploring the cognitive capacities of non human primates. For instance, as gray mouse lemurs identify their territory by urine washing, it would be interesting to determine whether they could be able to distinguish individual conspecific urines only by odor cues as it has been shown with rats $[10 ; 17]$. In addition, experimental studies of primate olfaction may prove useful in studies of aging: impairment in odor detection thresholds has been shown to occur in aged persons [18], and in persons with neurodegenerative diseases such as Alzheimer's disease where olfactory impairments have been evidenced in the early stages of the disease [19;20]. As the gray mouse lemur has proved to be a relevant primate model for ageing studies [8], our results open further the possibility to evaluate impairments in cognitive performances in relation to ageing and neurodegenerative diseases in a non human primate model.

\section{Acknowledgements}


M.J. is supported by G.R.A.L. (Groupe de Recherche sur la Maladie d'Alzheimer) and Ministère de l'Education Nationale. 


\section{References}

[1] Alterman, L.; Doyle, G.A.; Izard, M.K. Creatures of the Dark: The Nocturnal Prosimians. New York: Plenum Press; 1995.

[2] Perret, M. Chemocommunication in the reproductive function of mouse lemurs, In: Alterman, L. et al, eds. Creatures of the Dark: The Nocturnal Prosimians. New York: Plenum Press; 1995: 377-391.

[3] Perret, M. Environmental and social determinants of sexual function in the male lesser mouse lemur (Microcebus murinus). Folia Primatol. 59: 1-25; 1992.

[4] Perret, M. Social influences on oestrous cycle length and plasma progesterone concentrations in the female lesser mouse lemur (Microcebus murinus). J. Reprod. Fertil. 77: 303-311; 1986.

[5] Perret, M.; Schilling, A. Sexual responses to urinary chemosignals depend on photoperiod in a male primate. Physiol. Behav. 58: 633-639; 1995.

[6] Schilling, A.; Perret, M. Chemical signals and reproductive capacity in a male prosimian (Microcebus murinus). Chem. Senses. 12:143-158; 1987.

[7] Perret, M. Manipulation of sex ratio at birth by urinary cues in a prosimian primate. Behav. Ecol. Sociobiol. 38:259-266; 1996.

[8] Bons, N.; Mestre-Francés, N.; Petter, A. Microcebus murinus: modèle primate pour l'étude du cerveau de l'homme vieillissant. In: CNRS, eds. Primatologie. Marseille: ADRSC; 2000: 3-43. vol.3.

[9] Slotnick, B.; Hanford, L.; Hodos, W. Can rats acquire an olfactory learning set? J. Exp Psychol. Anim. Behav. Process. 26:399-415; 2000.

[10] Schellinck, H.M.; Brown, R.E.; Slotnick, B.M. Training rats to discriminate between the odors of individual conspecifics. Anim. Learn. Behav. 19:223-233; 1991. 
[11] Bodyak, N.; Slotnick, B. Performance of mice in an automated olfactometer: odor detection, discrimination and odor memory. Chem. Senses. 24:637-45; 1999.

[12] Siegel, S.; Castellan, N.J. Nonparametric statistics for the behavioral sciences. New York: McGraw-Hill; 1988.

[13] Slotnick, B.; Nigrosh, B.J. Olfactory stimulus control evaluated in a small animal olfactometer. Percept. Mot. Skills. 39:583-597; 1974.

[14] Slotnick, B.; Schellinck, H. Methods in olfactory research with rodents. In: Simon, S.A. and Nicolelis, M., eds. Frontiers and methods in chemosenses. Boca Raton: CRC Press; 2002: 21-61.

[15] Slotnick, B.M.; Kufera, A.; Silberberg, A.M. Olfactory learning and odor memory in the rat. Physiol. Behav. 50:555-561; 1991.

[16] Glaser, D.; Etzweiler, F.; Graf, R.; Neuner-Jehle, N.; Calame, J.; Mueller, P. The first odor threshold measurement in a non-human primate (Cebuella pygmaea; Callitrichidae) with a computerized olfactometer. In: Apfelbach, R. and MuellerSchwarze, D. Chemicals signals in Vertebrates VII, Advances in the Biosciences. Oxford: Elsevier; 1994: 445-455.

[17] Gheusi, G.; Goodall, G.; Dantzer, R. Individually distinctive odours represent individual conspecifics in rats. Anim. Behav. 53:935-944; 1997.

[18] Murphy, C.; Schubert, C.R.; Cruickshanks, K.J.; Klein, B.E.; Klein, R.; Nondahl, D.M. Prevalence of olfactory impairment in older adults. J.A.M.A. 288:2307-2312; 2002.

[19] Murphy, C. Loss of olfactory function in dementing disease. Physiol. Behav. 66:177$182 ; 1999$. 
[20] Moberg, P.J.; Doty, R.L.; Mahr, R.N.; Mesholam, R.I.; Arnold, S.E.; Turetsky, B.I.; Gur, R.E. Olfactory identification in elderly schizophrenia and Alzheimer's disease. Neurobiol. Aging. 18:163-167; 1997. 


\section{Figure legends}

Fig.1. Schematic representation of the olfactometer. Inset: details of the sampling tube in front of the test chamber. See text for details.

Fig.2. Comparison of performances during the three tasks. Task-1: fruity odor $v s$ pure air discrimination; Task-2: two fruity-odor discrimination; Task-3: reversal learning. Mean sessions \pm SD. $* \mathrm{p}<0.05$.

Fig.3. A typical individual performance during the three discrimination tasks. Dx represents the $\mathrm{x}^{\text {th }}$ session for the initial discrimination task, Tx for the transfer task and $\mathrm{Rx}$ for the reversal learning. Chance level (dashed line) and criterion level (continuous line) are indicated. One session corresponds to 40 consecutive trials. Note that in the two first sessions of the reversal learning, the number of correct responses were clearly below the chance level, thus indicating that animal has memorized previous tasks.

Fig.4. Analysis of correct responses during the three discrimination tasks of the same subject as in Fig.3. Dx represents the $\mathrm{x}^{\text {th }}$ session for the initial discrimination task, Tx for the transfer task and $\mathrm{Rx}$ for the reversal learning. Hits (white squares) and correct rejections (black squares) are indicated for the 40-trials sessions. Note that the general aspect of the correct rejections curve is superimposable to the individual performance presented in Figure 3. 
Figure 1

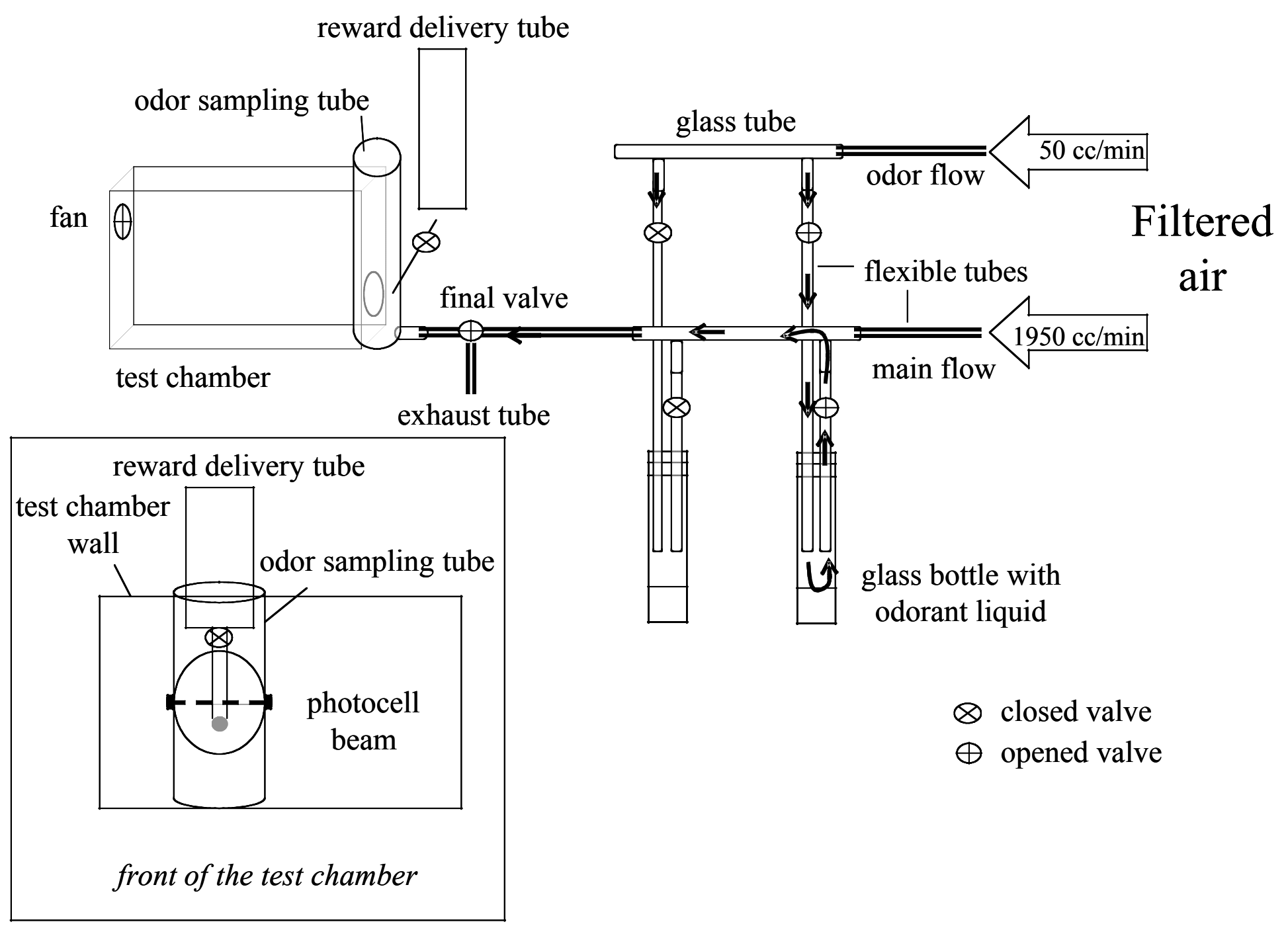


Figure 2

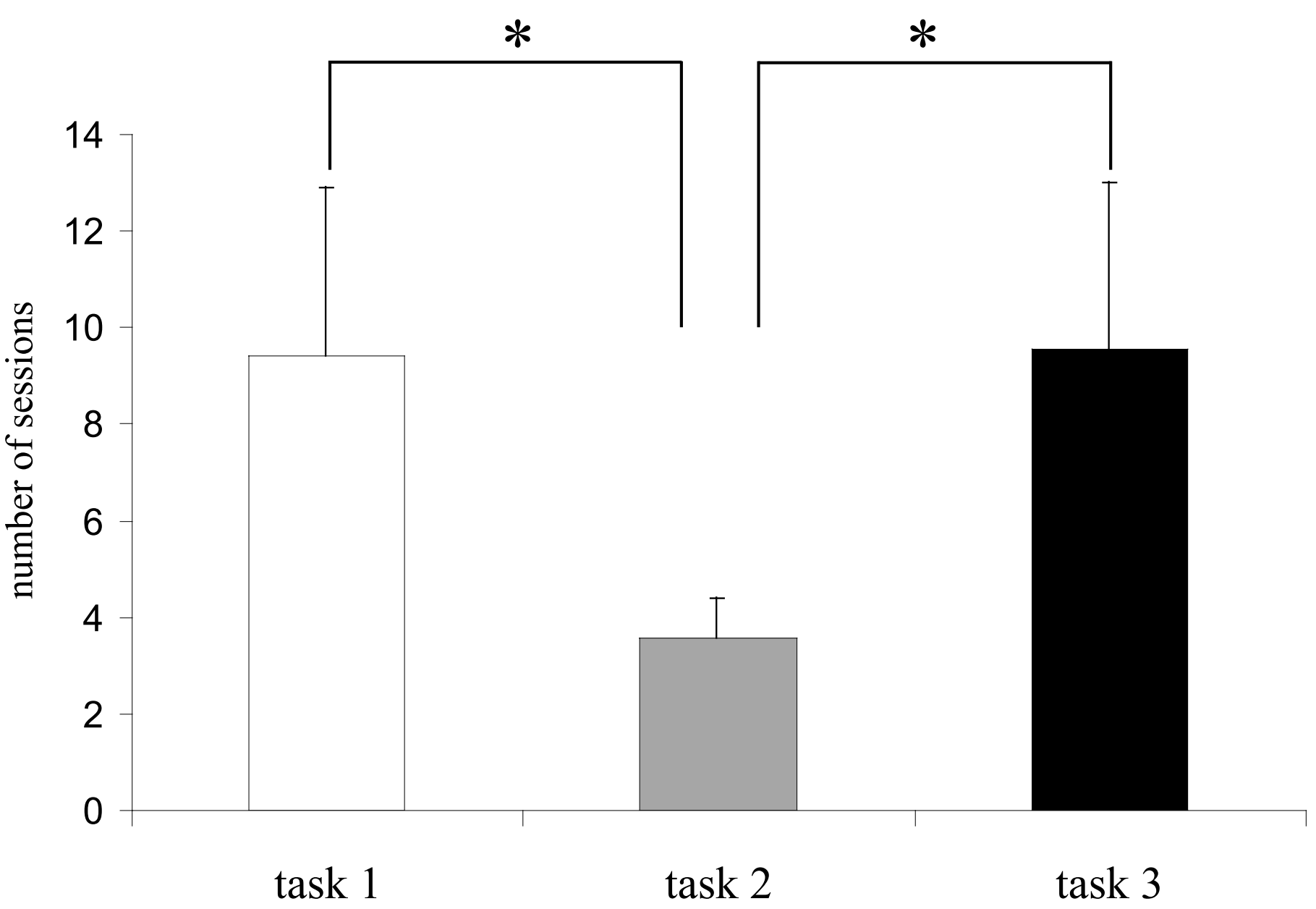


Figure 3

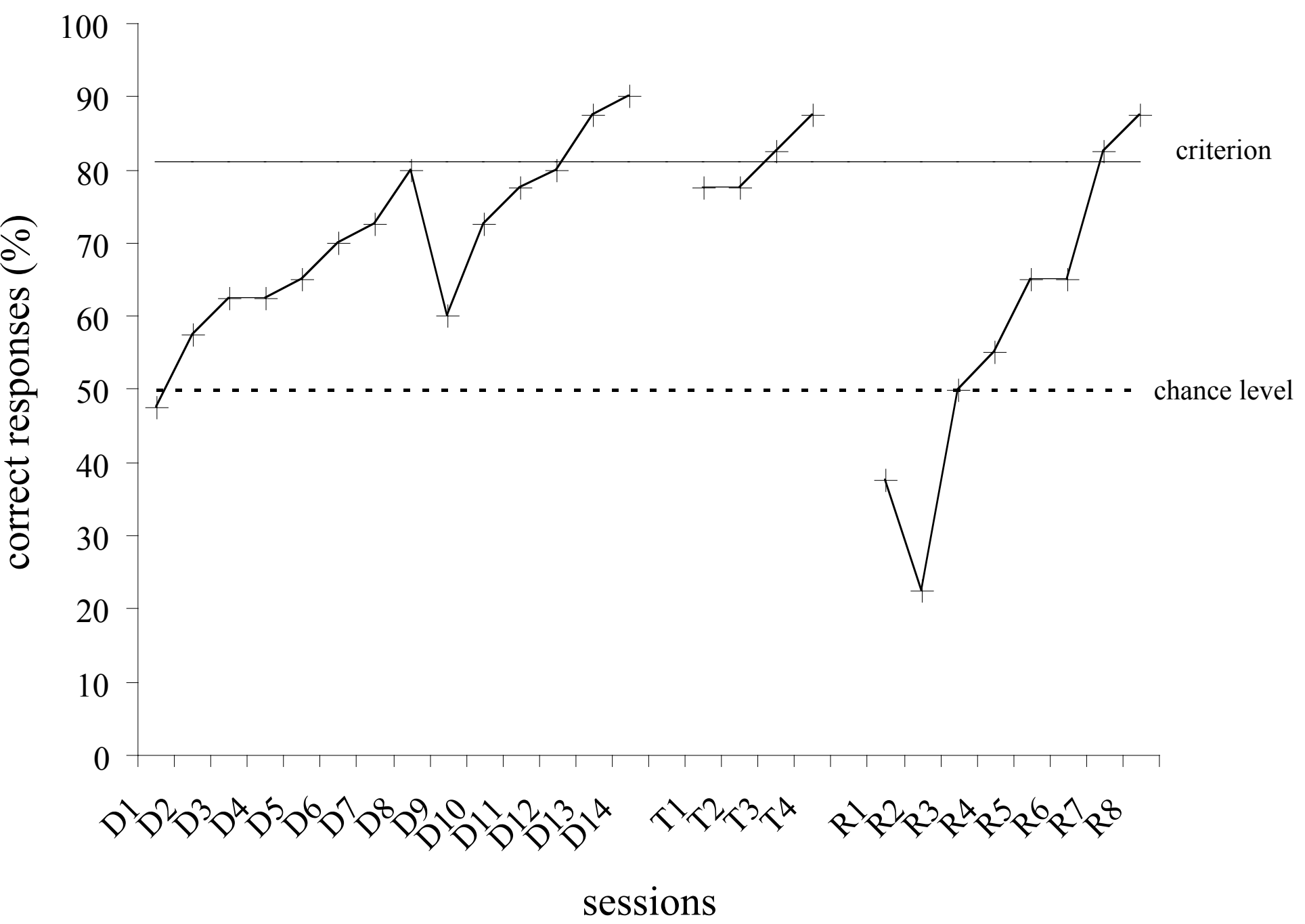


Figure 4

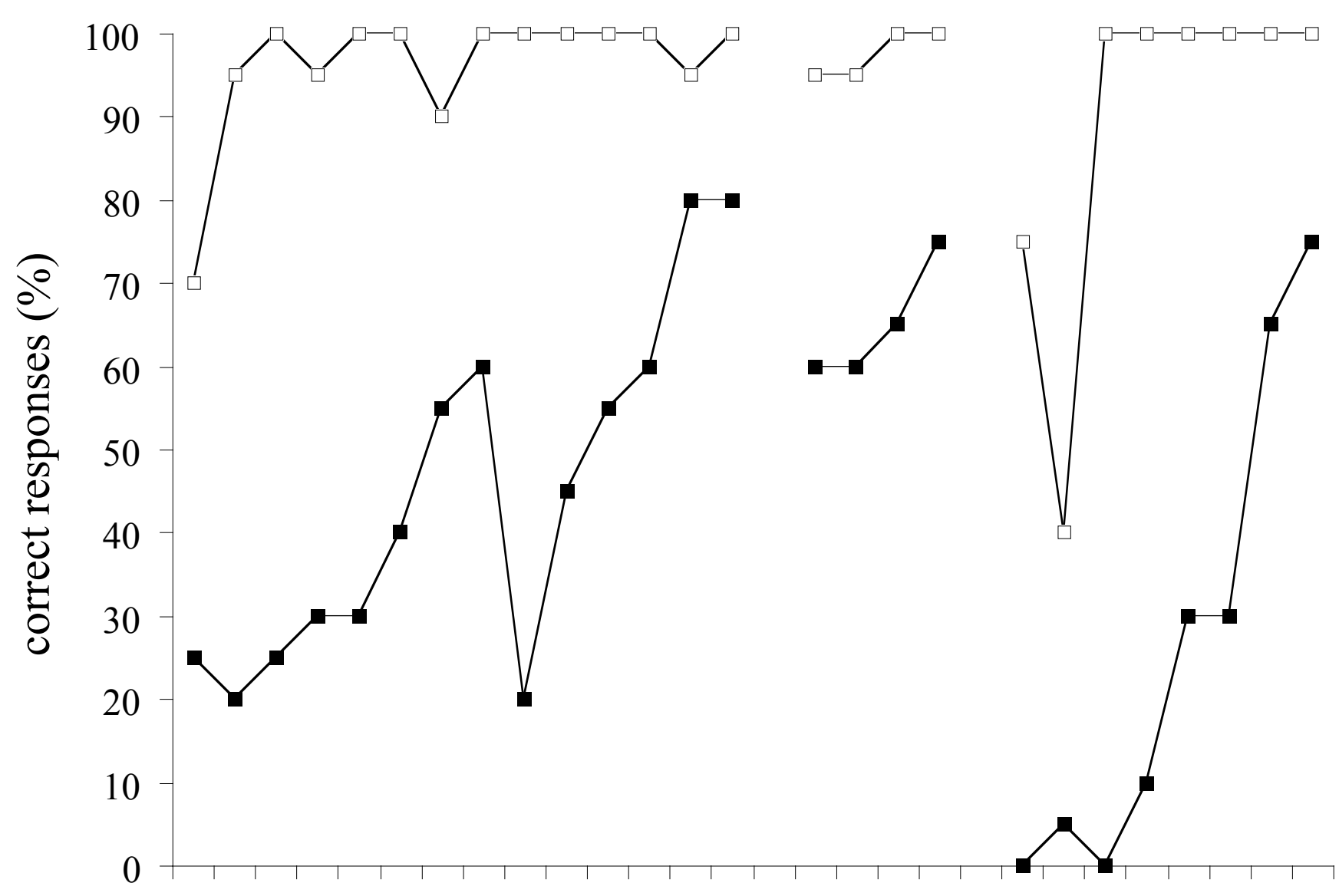

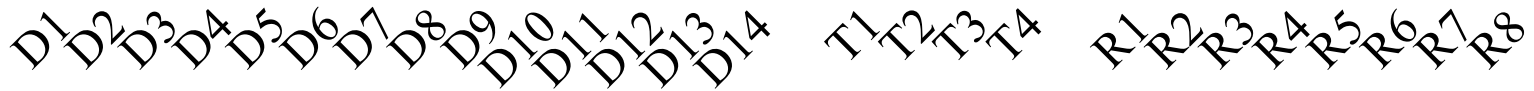

sessions 